\title{
Kinetic Study of Hydrodeoxygenation of Palmitic Acid as a Model Compound for Microalgae Oil over $\mathrm{Pt} / \gamma-\mathrm{Al}_{2} \mathrm{O}_{3}$
}

\author{
Lin Zhou* and Adeniyi Lawal \\ New Jersey Center for Microchemical Systems, Dept. of Chemical Engineering and Materials Science, Stevens Institute of \\ Technology, 1 Castle Point on Hudson, Hoboken, NJ 07030, USA
}

\section{Keywords:}

Hydrodeoxygenation (HDO)

Microalgae oil

Kinetic study

Power law

Langmuir-Hinshelwood

Eley-Rideal

$\mathrm{Pt} / \mathrm{Al}_{2} \mathrm{O}_{3}$

${ }^{*}$ Corresponding author,

Tel.; +1 201216 8314; Fax: +1 201216 8306; Email: lzhou4@stevens.edu

(C) 2016. This manuscript version is made available under the Elsevier user license http://www.elsevier.com/open-access/userlicense/1.0/ 


\begin{abstract}
The kinetics of hydrodeoxygenation (HDO) of palmitic acid over the $1 \% \mathrm{Pt} / \gamma-\mathrm{Al}_{2} \mathrm{O}_{3}$ catalyst was investigated in a microreactor using integral method. Kinetic data were collected under process conditions of industrial interest but in the regime with negligible heat and mass transfer limitations. For the first time, rate equations derived from three kinetic models (Power law, Langmuir-Hinshelwood, and Eley-Rideal) were investigated in data fitting through nonlinear regression using Levenberg-Marquardt algorithm, and evaluated based on proposed statistical and thermodynamics criteria. $\mathrm{H}_{2}$ was found to be adsorbed on the catalyst surface without dissociation, which is different from gaseous reaction with consistent dissociative adsorption of $\mathrm{H}_{2}$. The apparent activation energy is $60.3 \mathrm{~kJ} / \mathrm{mol}$, which is lower than the intrinsic activation energy of $92.9 \mathrm{~kJ} / \mathrm{mol}$ due to the exothermic adsorption of reactants. The proposed rate equations are expected to be applicable to liquid phase HDO of fatty acids, and not limited to palmitic acid. This complete kinetic study (including rate equations with specified kinetic parameters) fills an important knowledge gap in green diesel production from algae, and can be used for rational design of reactors and the determination of optimum operating conditions. Moreover, the presented work develops a systematic procedure for kinetic study by identifying the challenges that need to be overcome to obtain meaningful kinetic data.
\end{abstract}

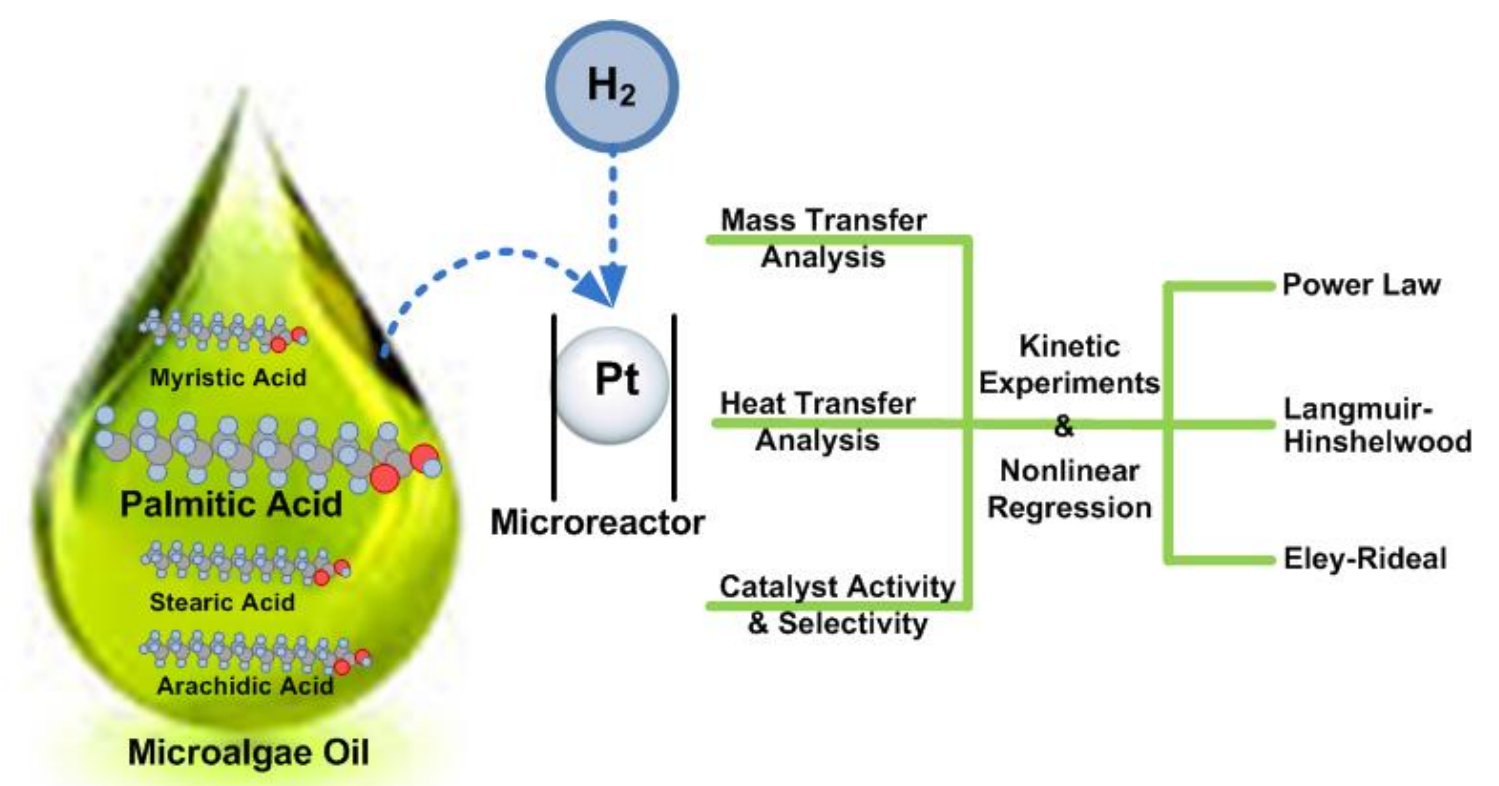




\section{Introduction}

According to the International Outlook 2014 released by the U.S. Energy Information Administration (EIA), the world liquid fuels consumption will rise $38 \%$ by $2040 .{ }^{1}$ As the biggest oil consumer of the world, the transportation sector is reported to account for about $20 \%$ of the global energy consumption. ${ }^{2}$ About $80 \%$ of today's transportation fuels are derived from petroleum. It has been reported that processes involving petroleum account for $31 \%$ of $\mathrm{CO}_{2}$ emissions, $24 \%$ of $\mathrm{NO}_{\mathrm{x}}$ emissions and $41 \%$ of nmVOC (non-methane Volatile Organic Compounds), ${ }^{3}$ and constitute the predominant source of air pollution. In addition, because fossil fuel reserves are finite, petroleum is not sustainable in the long term. These factors have encouraged the research and development of biomass-derived fuels, the utilization of which is a low-net carbon process. Compared with lignocellulosic biomass, oleaginous feedstock, comprising mainly triglycerides and free fatty acids, has higher energy content. ${ }^{4}$ Microalgae, as a source of non-edible oleaginous feedstock, has attracted researchers' attention due to its fast growth rate and high oil content. As reported previously, microalgae oil contains mainly C14 to C20 fatty acids with C16 fatty acid being predominant in the Nannochloropsis salina strain, which is the workhorse of the algae industry. ${ }^{5}$

Based on the experience on upgrading of vegetable oil, hydrotreating, which produces green diesel, is comparatively more advantageous than transesterification, the product of which is biodiesel. ${ }^{6}$ Performance studies of hydrodeoxygenation (HDO), the most critical step in hydrotreating of microalgae oil ${ }^{5-7}$ and vegetable oil ${ }^{8-10}$ have been demonstrated over different catalysts. Through the study of a wide range of model compounds, the mechanism of HDO of triglycerides was established. ${ }^{7-8,11-12}$ The HDO process starts with the saturation of double bonds in the alkyl chain, and is followed by the cleavage of C-O bond to produce fatty acids. Then the carboxylic group will be hydrogenated to form fatty aldehyde, which is finally converted to an even-numbered carbon hydrocarbon through Hydrodehydration (DHYD) with fatty alcohol as intermediate, or an odd-numbered carbon hydrocarbon via Hydrodecarboxylation (DCO2)/ Hydrodecarbonylation (DCO). Previous studies ${ }^{7,13-15}$ have investigated the group 10 metalsbased catalysts (Pt, Pd and Ni) in the HDO of lipids, including Triglycerides (TAG), fatty acid methyl esters (FAME), and free fatty acid (FFA). The results reveal that, over the group 10 metals-based catalysts, due to the similarities in their electronic structure, DCO route was preferred, and the hydrogenation of FFA to form aldehyde have been shown to be the ratelimiting step of the HDO reaction. ${ }^{7,13-15}$ The studies indicate that a cost-effective process of green diesel production from oleaginous feedstocks requires catalysts that demonstrate high activity in the conversion of carboxylic acids. ${ }^{13}$

The effectiveness of a catalyst in a reaction can be evaluated through its activation energy for that reaction. Although numerous studies have been conducted on the hydrotreating of fatty acids, limited kinetic models with specified kinetic parameters have been reported. The Langmuir-Hinshelwood kinetic expression was rarely investigated for this hydrotreating process. Boda et al. explain the pressure effect on the $\mathrm{HDO}$ of caprylic acid over $\mathrm{NiMo} / \gamma-\mathrm{Al}_{2} \mathrm{O}_{3}$ and $\mathrm{Pd} / \mathrm{C}$ using a rate equation derived from the competitive non-dissociative adsorption model. However, no kinetic parameters were determined for this system. ${ }^{13}$ Snare et al. studied the kinetics of HDO of stearic acid over $5 \% \mathrm{Pd} / \mathrm{C}$ without considering the role of $\mathrm{H}_{2}$ in the derived rate equation. The 
reported results show that the adsorption equilibrium constants for all reactants, intermediates and products are negligible, and the kinetic equation was reduced to a first order power-law form, which was found to be in good agreement with the experimental data. ${ }^{16}$ Due to the complexity of mechanistic model for the HDO reaction, most of the reported rate equations are in power-law form. The HDO kinetics of stearic acid based on a first order power law model was studied by Kumar et al, and the apparent activation energy was found to be $175.4 \mathrm{~kJ} / \mathrm{mol}$ over $15 \mathrm{wt} . \% \mathrm{Ni} / \gamma$ $\mathrm{Al}_{2} \mathrm{O}_{3},{ }^{17}$ which is greater than the value reported by Ayodele et al, $130.3 \mathrm{~kJ} / \mathrm{mol}$, over $\mathrm{FeMoO}_{\mathrm{x}} /$ Zeol. $^{18}$ Precious metal-based catalysts were found to be more effective in lowering activation energy than the base metal catalysts. The apparent activation energy of HDO of palm stearin fatty acid mixture over $5 \% \mathrm{Ru} / / \mathrm{Al}_{2} \mathrm{O}_{3}$ was reported to be $49.22 \mathrm{~kJ} / \mathrm{mol}$, with the order of 0.8 with respect to $\mathrm{H}_{2}$ partial pressure and 1.2 to liquid reactant. ${ }^{19}$

Considering the fact that there are only a few of applications of precious metal-based catalyst in the hydrotreating industry, the presented work aimed at investigating the Pt catalyst, with the $1 \%$ loading level being most commonly used for precious metal-based catalysts. This catalyst has been previously shown to have excellent performance in the HDO of microalgae oil, including inhibition of $\mathrm{CH}_{4}$ and coke formation. ${ }^{5}$ The objective of the current work is to establish a kinetic model with specified parameters that can be used in design of reactors for HDO of microalgae oil over $\mathrm{Pt} / \gamma-\mathrm{Al}_{2} \mathrm{O}_{3}$, which makes both scientific and industrial contribution to the production of green diesel. In terms of complex reaction feedstocks, such as lingo-cellulosic biooils, the lumping kinetics approach can be used, in which the chemical species with similar chemical reactivity are grouped into pseudo-species, the so-called lumps. ${ }^{20-22}$ However, since C16 fatty acids are the predominant fatty acids in microalgae oil, and the conversion of saturated FFA is the rate-limiting step, Palmitic Acid is used in this study as the model compound. The kinetic study results will be interpreted with the power law model, and the reaction mechanism will be presented via Langmuir-Hinshelwood and Eley-Rideal models.

\section{Experimental Section}

\subsection{Materials}

\section{Reactants}

Due to the complexity of biomass feedstocks (algae inclusive), a kinetic study similar to the presented work but applied to the real feedstock is theoretically not feasible, and the kinetic studies of major components (model compound) are widely used to obtain kinetic data for design purpose. As illustrated above, Palmitic Acid (P.A., $\mathrm{CH}_{3}\left(\mathrm{CH}_{2}\right)_{14} \mathrm{COOH}$ ) is selected as the model compound of microalgae oil in hydrodeoxygenation. P.A. was purchased from Fisher Scientific with $98 \%$ purity. At room temperature, similarly to the flowability of microalgae oil, which is semisolid, P.A. is a solid (white flakes), therefore pre-heating will be needed for continuous processing in a flow reactor system. There is however an alternative and practically feasible approach to processing these semisolids or solids, and that is the co-processing with petroleum refinery middle distillates, such as gas oil. The petroleum refinery has existing infrastructure for supply of hydrogen, hence the co-processing of alga oil with refinery middle distillates makes 
conversion of alga oil to green diesel practically realizable. Therefore, to make the proposed kinetic models applicable to hydrotreating of alga oil as it would be practiced industrially, (e.g.co-processing alga oil with petroleum refinery middle distillates, gas oil), the selected solvent should be a hydrocarbon that mimics the solvent properties of gas oil. In addition, it should also satisfy the following requirements: (1) not reactive under experimental conditions (2) high boiling point to maintain low vapor pressure under experimental condition (3) low melting point to keep it in melted state at room temperature. Based on all these considerations, ndodecane $(99+\%$, Alfa Aesar) is used as solvent in this study.

Limited by the HPLC pump operating temperature range (of $10{ }^{\circ} \mathrm{C}$ to $30{ }^{\circ} \mathrm{C}$ ), feed solution cannot be preheated to increase the P.A. solubility in the feed reservoir. Therefore, $1 \mathrm{~g}$ of P.A. is dissolved in $99 \mathrm{~g}$ of dodecane to make $1 \mathrm{wt} \%$ solution. In order to minimize the potential sources of errors from sample preparation and $\mathrm{GC}$ analysis, Eicosane $\left(\mathrm{C}_{20} \mathrm{H}_{42}\right)$ was added into the feed solution as internal standard due to its thermal and chemical stability. The feed solution is sonicated for 2 hours to ensure complete mixing. Ultra-high purity (5.0 grade) Hydrogen was purchased from Praxair.

\section{Catalyst}

Based on our previous catalyst evaluation on hydrodeoxygenation of microalgae (Nannochloropsis salina) oil, to maximize the application of the proposed model and to provide reproducible and reliable kinetic models, $1 \% \mathrm{Pt} / \gamma-\mathrm{Al}_{2} \mathrm{O}_{3}$ (Alfa Aesar) is used in the present kinetic study. ${ }^{5}$ Based on the previously published and extensive experimental studies from our group, including hydrogenation of o-nitroanisole, ${ }^{23}$ and aromatic nitro ketone, ${ }^{24}$ and the hydrodeoxygenation of different reactants at different concentrations (pyrolysis oil, ${ }^{25} 2$ methoxy-4-propylphenol, ${ }^{26}$ and acetic acid ${ }^{27}$ ), , using different catalysts in a microreactor, it was found that the reactions were not limited by internal mass transfer, when the particle size of the catalyst ranges from $75-150 \mu \mathrm{m}$. Therefore, catalyst was ground and sieved to this particle size range, and the theoretical evaluation is considered to be adequate for estimating the internal mass transfer limitation effect.

\subsection{Experimental Setup and Procedure}

The schematic of the setup for kinetic study of P.A. hydrodeoxygenation is shown in Figure 1. Since meaningful kinetic data can only be collected in the region where heat and mass transfer limitations are all negligible, microreactor, which features enhanced mass and heat transfer characteristics, is used in this study. The inner diameter of the SS316L microreactor used was $0.762 \mathrm{~mm}$ and the length was varied from $3 \mathrm{~cm}$ to $13.3 \mathrm{~cm}$ depending on the catalyst loading amount required by the experiment. Two pieces of $0.3175 \mathrm{~cm}$ outer diameter SS316L tubing packed with glass beads $(90 \mu \mathrm{m})$ were connected to the entrance and exit of the microreactor. In order to retain the packed particles in each tubing section, Hastelloy micro filter-cloth (200X1150 meshes, Unique Wire Weaving Co., Hillside, NJ) was placed at the end of each tubing. The reactor was then placed in an electric furnace with digital temperature control and readout, and a hand-held thermal meter was also used to further confirm the temperature in the furnace. It should be noted that the temperature in this study was reported as reactor wall 
temperature. Two pressure transmitters were used to measure the pressure at the entrance and exit of the reactor, and the system pressure was adjusted by a back pressure regulator (BPR) installed downstream. The flow rate of compressed gas was regulated by the mass flow controller (sccm), which was calibrated routinely with an Agilent ADM 2000 universal gas flowmeter before and after each run. In order to prevent the precipitation of P.A. and the HDO product from dodecane, heat trace was added to keep the temperature of the region surrounding the reactor system at $22^{\circ} \mathrm{C}$ or slightly higher.

Before each run, reactor system was purged with hydrogen for 30 minutes at room temperature and atmospheric pressure to ensure the system was filled with pure hydrogen. Then, in situ reduction of fresh catalyst was conducted by increasing the system pressure to 500psig and temperature to $310^{\circ} \mathrm{C}$ with hydrogen flow rate of $50 \mathrm{sccm}$. After adjusting to reaction temperature, pressure and hydrogen flow rate, and letting the system stabilize for 30 minutes, liquid feed was pumped by the HPLC pump to the T-mixer where it contacts the hydrogen feed to form a slug flow before entering the reactor. The reduction in the cross sectional area of the reactor system from the entrance to catalyst bed ensures the uniform wetting of the catalyst by the reagents. During the experiment, liquid sample was collected from the sample valve every hour and analyzed. The remaining product would flow into the gas-liquid separator, with liquid being condensed in the separator flask and gas being vented to the hood. After the experiment, the system was cleaned by first pumping hexane through it at $4 \mathrm{ml} / \mathrm{min}$ for 30 minutes with the BPR fully opened, followed by purging with nitrogen for 1hour to get rid of any liquid residue from the system.

\subsection{Product Analysis}

Based on the analysis of the liquid product from a preliminary run, as depicted in Figure 2 , the liquid products of HDO of P.A. were Pentadecane $\left(\mathrm{C}_{15} \mathrm{H}_{32}\right)$, Hexadecane $\left(\mathrm{C}_{16} \mathrm{H}_{34}\right)$, Hexadecanal $\left(\mathrm{C}_{15} \mathrm{H}_{31} \mathrm{CHO}\right)$, Hexadecanol $\left(\mathrm{C}_{16} \mathrm{H}_{33} \mathrm{OH}\right)$, and Palmityl Palmitate $\left(\mathrm{C}_{15} \mathrm{H}_{31} \mathrm{COOC}_{16} \mathrm{H}_{33}\right)$, which confirmed the reaction mechanism previously reported for HDO of different fatty acids over different catalysts. ${ }^{7-8}$ The identification and quantification of all compounds in the liquid product was done using a Varian 450 Gas Chromatograph (GC) equipped with a CP-8400 Autosampler under the conditions listed below:

Column: ZB-FFAP capillary column $(30 \mathrm{~m} \times 0.32 \mathrm{~mm} \times 1 \mu \mathrm{m})$

Oven Profile: $100^{\circ} \mathrm{C}(1 \mathrm{~min}), 15^{\circ} \mathrm{C} / \mathrm{min}$ to $160^{\circ} \mathrm{C}, 8^{\circ} \mathrm{C} / \mathrm{min}$ to $260^{\circ} \mathrm{C}(35 \mathrm{~min})$

Carrier Gas: Helium, $2.4 \mathrm{ml} / \mathrm{min}$

Injection: $280^{\circ} \mathrm{C}, 0.5 \mu \mathrm{L}, 1: 10$ split

Detector: FID, $280^{\circ} \mathrm{C}$

External calibration was conducted before analyzing each batch of samples to obtain the response factor and retention time of each compound, which were used in the calculation of the concentration $\left(\mathrm{mol} / \mathrm{m}^{3}\right)$ of respective compounds. Since the feed solution was very dilute, which was essentially dodecane ( $99 \mathrm{wt} \%$ ), the density of liquid flow was assumed unchanged before and after the reaction. 
Therefore, the molar flow rate of P.A. at exit is defined as

$$
F_{P . A . o u t}\left(\frac{m o l}{s}\right)=\text { concentration of P.A. at exit } \times \text { liquid flow rate }
$$

The yield of $\mathrm{C}_{15} \mathrm{H}_{32}$, the major product was calculated on the total product mass basis

$$
C_{15} H_{32} \text { Yield (\%) }=\frac{\text { total mass of } C_{15} H_{32} \text { in product }}{\text { total mass of all } H D O \text { liquid products }} \times 100
$$

The yield of total product is defined as:

Total Product Yield $(\%)=\frac{\text { Total moles of liquid products }}{\text { Total moles of the theoretical yield of liquid produt }} \times 100$

Space-time consumption (STC) of P.A. is defined as

$$
S T C_{P . A .}=\frac{\text { moles of P.A.consumed } / \text { time }}{\text { mass of catalyst }}
$$

Conversion of P.A. is defined as

$$
\text { Conversion of P.A. (\%) }=\frac{\text { moles of P.A.consumed }}{\text { moles of P.A.fed }} \times 100
$$

After each run, a check was made to ensure that material balance was satisfied using the following equation:

$-5 \%<\frac{\text { moles of P.A.consumed-total moles of liquid product }}{\text { moles of P.A.consumed }}<5 \%$

It should be noted that two moles of P.A. are required to form one mole of Palmityl Palmitate. Therefore, when performing the material balance, the number of moles of produced Palmityl Palmitate contributed to the total moles of liquid product was twice the moles of Palmityl Palmitate measured in product.

\section{Results and Discussion}

\subsection{Mass Transfer Analysis}

\subsubsection{Analysis of External Mass Transfer Limitation}

Based on the relevant fluid flow characterization study, ${ }^{23}$ all the kinetic study data was collected in Taylor flow regime, comprising alternate liquid slugs and gas bubbles. The main external mass transfer resistances, for this three phase reaction of palmitic acid with hydrogen on the $\gamma$-alumina supported catalyst, occur at the gas-liquid and liquid-solid interfaces, with the former being predominant. ${ }^{6}$ Due to the dependence of mass transfer rates through interfaces on flow velocity, the overall external mass transfer limitation can be evaluated experimentally by studying the change of Space-time-consumption (STC) of P.A. at different superficial flow velocities. Superficial flow velocity was varied by changing gas and liquid flow rates and reactor length (the amount of catalyst), while keeping the other process conditions, including reactor ID, gas to liquid ratio, residence time, reaction temperature and pressure, constant. ${ }^{5}$ The 
experimental results depicted in Figure 3 show that the STC of P.A. is independent of the superficial flow velocity in the studied range. That means the reaction is not limited by external mass transfer even at the lowest flow velocity of $0.49 \mathrm{~m} / \mathrm{s}$, which was subsequently chosen as the baseline velocity for the kinetic studies.

\subsubsection{Analysis of Internal Mass Transfer Limitation}

Internal mass transfer refers to the diffusion of reactants from the catalyst pellet pore entrance into the catalyst. ${ }^{25}$ When the concentration profiles of reactants inside the pores show significant variation from the catalyst surface to its center, reactions are considered to be limited by internal mass transfer. This concentration variation through the catalyst pellet is estimated by calculating the Weisz-Prater parameter $\left(\mathrm{C}_{\mathrm{wp}}\right)$ defined as: $:^{28}$

$C_{w p}=\frac{\text { actual reaction rate }}{\text { a diffusion rate }}=\frac{-r_{A(\text { obs })}^{\prime} \rho_{P} R^{2}}{D_{e} C_{A s}}$

Where

$-r_{A(o b s)}^{\prime}:$ Observed reaction rate, $1.066 \times 10^{-3} \mathrm{~g}$ P.A./ g cat. $/ \mathrm{s}$.

$\rho_{P}$ : Density of catalyst pellets, $0.29 \times 10^{6} \mathrm{~g}$ cat. $/ \mathrm{m}^{3}$.

R: Characteristic diameter of the catalyst pellets, $112.5 \times 10^{-6} \mathrm{~m}$.

$\mathrm{C}_{\mathrm{AS}}$ : Hydrogen concentration at the external surface of the catalyst pellets, which is the hydrogen solubility in dodecane approximately, $360 \mathrm{~g} / \mathrm{m}^{3}$.

$D_{e}$ : Effective diffusivity of hydrogen in the catalyst pellets, $D_{e}=\left(D_{A B} \varphi_{p} \sigma_{C}\right) / \tau$, where $D_{A B}$ : Binary diffusivity of hydrogen in dodecane, $1.12 \times 10^{-7} \mathrm{~m}^{2} / \mathrm{s} ;{ }^{29} \varphi_{\mathrm{p}}$ : Porosity of the catalyst pellets, $0.5 ; \sigma_{\mathrm{C}}$ : Catalyst constriction factor, $0.8 ; \tau$ : catalyst tortuosity, $2{ }^{25} \mathrm{Then}$, the $\mathrm{D}_{\mathrm{e}}$ is calculated to be between $2.24 \times 10^{-8} \mathrm{~m}^{2} / \mathrm{s}$.

The calculated Weisz-Prater parameter is 0.485 , which is less than 1 . According to the definition of $\mathrm{C}_{\mathrm{wp}}$, the actual reaction rate in this study is less than the diffusion rate, and the reaction is not controlled by internal mass transfer.

\subsection{Heat Transfer Analysis}

Poor heat transfer characteristics will result in large temperature gradient within the reactor, which will mask the true kinetics of the reaction because reaction will occur in the 
reactor at different rates due to the temperature gradient. Therefore, in order to ensure that experimental data collected reflect only the kinetics, heat transfer limitations will be analyzed for the following three regions: 1 . Intra-particle ; 2 . Interphase between the external surface of the particles and fluid adjacent to them; and 3. Inter-particle or intra-reactor (between the local fluid regions or catalyst particles), which reflects gradients within the reactor as a whole. ${ }^{27}$ To determine whether heat transfer limitations exist in any domain depends on the values of literature defined criteria. ${ }^{30-31}$ Mears ${ }^{31}$ suggested that when the Biot number (Bi) is much smaller than 10 , the heat transfer resistances decrease in the order of inter-particle $>$ inter-phase $>$ intraparticle. The Biot number is the ratio of thermal resistance of the particle to that of the film around the particle.

$$
B i=\frac{\text { thermal resistance of the particle }}{\text { thermal resistance of the film around the particle }}=\frac{h d_{p}}{\lambda}
$$

where: $\mathrm{h}\left(10-100 \mathrm{~W} / \mathrm{m}^{2} / \mathrm{k}\right)$ is the heat transfer coefficient, ${ }^{31} \mathrm{~d}_{\mathrm{p}}(112.5 \mu \mathrm{m})$ is the diameter of the catalyst particle, and $\lambda$ (in the order of $0.1 \mathrm{~W} / \mathrm{m} / \mathrm{K}^{32}$ ) is the effective thermal conductivity of porous catalyst. In the present work, $\mathrm{Bi}<<10$ indicating that inter-particle heat transfer limitations predominate compared to the other two. Inter-particle transport effects occur both radially and axially within the reactor.

Axial Heat Transfer Limitation When the ratio of axial length of the reactor to the catalyst particle size is much greater than 20, the axial heat transport effect can be neglected. In this study, the minimum ratio used for kinetic study is 267 , thus the axial heat transfer limitation is negligible.

Radial Heat Transfer Limitation Radial heat transport limitations could be evaluated by calculating Damkohler number (Da) for heat transfer, ${ }^{30}$ and comparing it to the value of $0.4\left(\mathrm{RT}_{\mathrm{w}} / \mathrm{E}_{\mathrm{a}}\right)$, as shown by the equation below:

$D_{a}=\left|\frac{-\Delta H\left(-R_{o b s}\right)(1-\varepsilon) R_{0}^{2}}{\lambda T_{w}(1+b)}\right|<0.4 \frac{R T_{w}}{E_{a}}$

When the above inequality holds, the radial temperature difference in the reactor would be less than $5 \%$ of average cross-sectional temperature.

In this work, where

- $\Delta \mathrm{H}=49.7 \times 10^{3} \mathrm{~J} / \mathrm{mol}$ is the heat of reaction.

- $-\mathrm{R}_{\mathrm{obs}}=4.34 \mathrm{~mol} / \mathrm{m}^{3} / \mathrm{s}$ is observed reaction rate at temperature $\left(\mathrm{T}_{\mathrm{w}}\right)$ of $633.15 \mathrm{~K}$.

- $\varepsilon=0.3$ is the bed porosity.

- $\mathrm{R}_{0}=0.000381 \mathrm{~m}$ is the inner radius of the microreactor.

- $b=0$ is the ratio of diluent to catalyst volume.

- $\mathrm{E}_{\mathrm{a}}=60.30 \times 10^{3} \mathrm{~J} / \mathrm{mol}$ is activation energy.

the left side (0.000346) is much smaller than the right side (0.0349), indicating that the radial temperature gradient in the reactor is negligible. Based on the heat transfer analysis, the kinetic study experiment was not conducted in the heat transfer controlling regime. 


\subsection{Catalyst Activity and Selectivity}

Microalgae oil, as reported previously, ${ }^{5-6}$ is a complex material. In addition to the oxygen atom $\mathrm{O}$, the non-lipids portion also contains heteroatoms like $\mathrm{N}, \mathrm{S}, \mathrm{P}$, which may cause catalyst deactivation. According to our experience with microalgae upgrading techniques, the deactivation study using model compounds is of limited significance, and therefore, not included in this presented kinetic study.

As is well known to researchers in industrial catalysis, fresh catalysts are always super active before subsequently stabilizing in performance in the reactor system. The initial decrease in catalyst activity is not considered as deactivation but the transition to stability. Industrial catalysis texts make reference to this behavior in performance of fresh catalysts. It has also been confirmed in previous performance study on HDO of microalgae oil over $1 \% \mathrm{Pt}$ catalyst, which showed that the catalyst activity and selectivity reached stable state around 4 to 5-hour time-onstream. $^{5}$ As shown in Figure 4 (a)\& (b), with the lowest catalyst loading used in this study, the stability of catalyst activity and selectivity was studied in terms of P.A. conversion and the yield of main product, $\mathrm{C}_{15} \mathrm{H}_{32}$ respectively. The activity of the catalyst dropped rapidly during the first 5 hours, and then remained stable for 5 hours; while its selectivity didn't change much with timeon-stream. The stability of catalyst performance can always be preserved by increasing catalyst loading. ${ }^{5-6}$ Moreover, catalyst regeneration, which was conducted every 2 hours on-stream following the same catalyst reduction procedure, was found to be effective in restoring the catalyst performance, as reflected by the total product yield (Figure 4 (c)). Therefore, all kinetic data was collected between 8 to 10 hours on-stream time, during which the catalyst deactivation effect was negligible.

\subsection{Kinetic Study}

\subsubsection{Experimental results}

Preliminary results showed that the lowest conversion of P.A. obtained in the shortest microreactor, $3 \mathrm{~cm}$ (14.2 $\mathrm{mg} \mathrm{1 \%} \mathrm{Pt} \mathrm{catalyst),} \mathrm{at} \mathrm{process} \mathrm{conditions} \mathrm{of} \mathrm{interests,} \mathrm{was} \mathrm{higher} \mathrm{than}$ $10 \%$. Therefore, integral method is used in this kinetic study. By performing mole balance on P.A. in the microreactor, the consumption rate of P.A. in HDO is expressed through measurable process parameters, and is given by

$$
\frac{d F_{P . A .}}{d w}=r_{P . A .}
$$

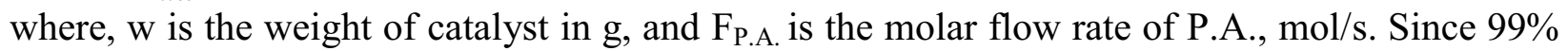
of the processed liquid feed was dodecane, the liquid volume flow rate at the entrance and exit was considered to be unchanged, and $F_{\text {P.A. out }}$ can be calculated by multiplying P.A. concentration $\left(\mathrm{mol} / \mathrm{m}^{3}\right)$ by liquid flow rate $\left(\mathrm{m}^{3} / \mathrm{s}\right)$. The consumption rate of P.A., $\mathrm{r}_{\text {P.A. }}$, will be substituted by rate equations derived from proposed reaction mechanisms, which is a function of reactants concentration and reaction temperature. With negligible heat and mass transfer limitations, $r_{P . A}$. is constant radially, but changes axially along the reactor due to the change in reactants concentration, i.e., $r_{P . A}=f(z)$ where $\mathrm{z}$ is the reactor axial coordinate. It is challenging practically to measure the $r_{P . A}$ locally along the reactor. Therefore, experiments were conducted in reactors 
with different length but same catalyst packing density. As shown in Figure 5 and Figure 6, by

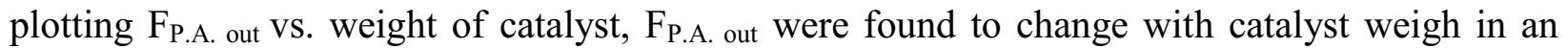
exponential manner, therefore, the reaction rate can be calculated by numerically differentiating the corresponding exponential functions.

\subsubsection{Kinetic modelling}

The obtained kinetic data from 3.4.1. was fitted to different rate equations. It should be noted that, since the pressure of $\mathrm{H}_{2}$ is the commonly used process parameter in the control of hydrotreating process, $\mathrm{H}_{2}$ pressure was used in all proposed rate equations, but not the concentration of dissolved $\mathrm{H}_{2}$.

The kinetic parameters in each rate equation were estimated through nonlinear regression using Levenberg-Marquardt algorithm in Polymath. The goodness of fit of the kinetic models was evaluated by comparing the reaction rates obtained from the model with the experimental data. The statistical information in the Polymath results was used to assess the quality of the proposed model. Also, the obtained kinetic parameters had to satisfy certain constraints for model discrimination:

1) Reaction rate constants and adsorption equilibrium constants should be positive.

2) Activation energy should be positive.

3) $\mathrm{R}^{2}>95 \%$.

4) The $95 \%$ confidence interval should be much less than the corresponding value itself.

Selected rate equations derived from different kinetic models are listed in Table 1.

\section{a. Empirical modeling (Power-law)}

With the assumption that the adsorption of reaction intermediates and products was negligible, HDO rate of P.A. was fitted to the power law model (Table 1), in which, $\mathrm{r}_{\mathrm{P} . \mathrm{A} \text {. }}$ is the consumption rate of P.A., $\mathrm{k}_{\mathrm{rxn}}$ is the rate constant, $\mathrm{C}_{\mathrm{P} . \mathrm{A}}$ is the P.A. concentration, $\mathrm{P}_{\mathrm{H} 2}$ is the hydrogen partial pressure, and $\alpha$ and $\beta$ are reaction orders. Values of $\alpha$ or $\beta \approx 1$ indicate a weak adsorption of reactants on catalyst surface, whereas much lower values of the order $(\ll 1)$ will imply a strong adsorption. $^{33}$

\section{b. Mechanistic conjecture}

In a typical heterogeneous catalytic reaction, three sequential steps are involved: a) Adsorption of reactants onto catalyst surface; b) Surface reaction; c) Desorption of the products from the catalyst surface. The reaction mechanisms giving rise to the reaction rates of HDO of P.A. can be described via two different approaches:

(1) Langmuir-Hinshelwood mechanism, which assumes both reactants are adsorbed on the catalyst surface. In this study, rate equations derived from both single-site and dual-site dissociative and non-dissociative adsorption of $\mathrm{H}_{2}$ and P.A. mechanisms were investigated and evaluated through data fitting, where $\mathrm{k}_{\mathrm{rxn}}$ is the rate constant, $\mathrm{K}_{\mathrm{H} 2}$ and 
$\mathrm{K}_{\text {P.A. }}$ are the equilibrium adsorption constants of $\mathrm{H}_{2}$ and P.A. respectively. Based on the statistical constraints stated above, the experimental data was best fitted to the rate model that assumes the rate-limiting step to be surface reaction with dual-site non-dissociative adsorption of $\mathrm{H}_{2}$ and P.A..

(2) Eley-Rideal mechanism. Due to the steric constraint and the geometric requirement for site adsorption, ${ }^{34}$ one reactant is adsorbed, while the other non-adsorbed reactants remains in the fluid phase. According to the model fitting results, $\mathrm{H}_{2}$ was adsorbed on the catalyst surface without dissociation, and reacted with P.A. molecule from the bulk phase.

The two types of mechanistic models are based on different assumptions on the adsorption step. For LHHW model, both reactants are adsorbed on the catalyst surface, while only one reactant is adsorbed on the catalyst surface for the Eley-Rideal mechanism. Therefore, both mechanisms were considered. The proposed Langmuir-Hinshelwood rate equation reduces to Eley-Rideal rate equation at low P.A. concentration $\left(K_{\text {P.A.A.A. }} C_{\text {P. }} \ll 1\right)$, and also they can both be shown to convert to a form with a reaction order of 1 with respect to each reactant, which confirms the validity of the power law model. For example, when $1 \ll \mathrm{K}_{\text {P.A. }} \mathrm{C}_{\text {P.A. }}$ and $\mathrm{K}_{\mathrm{H} 2} \mathrm{P}_{\mathrm{H} 2} \ll 1$, Langmuir-Hinshelwood model simplifies to $r_{P . A .}=k_{r x n} K_{H_{2}} P_{H_{2}}$, which indicates the reaction order of $\mathrm{H}_{2}$ is 1 .

Based on the criteria listed above, as shown in Table 2, three rate equations derived from (1) power law, (2) Langmuir-Hinshelwood mechanism with the assumption of due site nondissociative $\mathrm{H}_{2}$ and P.A., and (3) Eley-Rideal mechanism with the assumption of nondissociative adsorption of $\mathrm{H}_{2}$ and non-adsorbed P.A., were found to fit the experimental data well, and were considered for further calculation of kinetic constants. All kinetic parameters listed in Table 1 were assumed to follow the Arrhenius relation, $\mathrm{K}_{\mathrm{i}}=\mathrm{A}_{\mathrm{i}} \mathrm{e}^{-\mathrm{Ei} / \mathrm{RT}}$. By plotting $\ln \mathrm{K}_{\mathrm{i}}$ against 1/T, all pre-exponential factors (A, B, C), as well as the Activation Energy (Ea) and Heat of adsorption $\left(\Delta \mathrm{H}_{\mathrm{H} 2}, \Delta \mathrm{H}_{\text {P.A. }}\right)$ are determined from intercept and slope of Arrhenius plot (Table 2). It needs to be stated that, since no independently measurable thermodynamic data for adsorption equilibrium constants was involved, the regression analysis of the experimental data was performed purely on mathematical basis. Therefore, the thermodynamic significance of the adsorption constants cannot be established.

The activation energy $(60.3 \mathrm{~kJ} / \mathrm{mol})$ obtained from Power Law and Eley-Rideal models is in fact an apparent activation energy, affected by the adsorption terms, which is typically lower than the intrinsic activation energy $(92.9 \mathrm{~kJ} / \mathrm{mol})$ obtained from Langmuir-Hinshelwood model. ${ }^{19,35}$ Compared to the activation energy reported previously in the literature (175.4 $\mathrm{kJ} / \mathrm{mol},{ }^{17} 130.3 \mathrm{~kJ} / \mathrm{mol},{ }^{18}$ mentioned in Introduction section) for other base metal-based catalysts, $1 \% \mathrm{Pt} / \gamma-\mathrm{Al}_{2} \mathrm{O}_{3}$ appears to be more effective in lowering the energy barrier of $\mathrm{HDO}$, thereby enhancing the conversion rate of P.A.. As expected, the adsorption step is exothermic, and negative $\Delta \mathrm{H}$ value was obtained. The small adsorption heat of $\mathrm{H}_{2}$ obtained from mechanistic model indicates the weak adsorption of $\mathrm{H}_{2}$ onto the catalyst surface, which is in agreement with the power law model results with $\beta \approx 1$. Furthermore, $\mathrm{H}_{2}$ was found to be non-dissociative when 
adsorbed on catalyst surface in this study, and similar results were also reported elsewhere. ${ }^{19,24,26,36}$ It should be stated that, in gaseous reactions, $\mathrm{H}_{2}$ was generally found to adsorb on precious metal catalyst, especially $\mathrm{Pt}$, with dissociation. In contrast, in the current work, our observations indicate that the adsorption of $\mathrm{H}_{2}$ on catalyst surface is affected by the presence of the liquid reagent, therefore, the derived rate equations only apply to liquid phase HDO. However, based on the previously reported experimental studies, which conclude that the HDO rates of different fatty acids are independent of the fatty acid chain length, ${ }^{37-39}$ the derived rate equations are also applicable to other fatty acids with different chain lengths.

\section{Conclusions}

Kinetic study on hydrodeoxygenation of microalgae oil using palmitic acid as a model compound has been conducted over reduced $1 \% \mathrm{Pt} / \gamma-\mathrm{Al}_{2} \mathrm{O}_{3}$ in a microreactor. In order to develop a kinetic model that can be applied at temperatures and pressures relevant to industrial process conditions, all kinetic data was collected over the range of temperature of 340 to $360^{\circ} \mathrm{C}$, pressure of 300 to $500 \mathrm{psig}$ at constant hydrogen to oil ratio of $1000 \mathrm{SmL} / \mathrm{mL}$. Based on the heat and mass transfer analysis and catalyst stability study, all kinetic data was collected in the regime with negligible mass and heat transfer limitations and stable catalyst activity and selectivity. Rate equations derived from three different models (Power Law, Langmuir-Hinshelwood, and EleyRideal models) were investigated in data fitting through nonlinear regression using LevenbergMarquardt algorithm in Polymath, and the best fitted rate equations were reported based on the proposed model discrimination constraints. In this presented gas-liquid reaction, $\mathrm{H}_{2}$ was found to be adsorbed on the catalyst surface without dissociation, which is different from gaseous reaction with consistent dissociative adsorption of $\mathrm{H}_{2}$. The apparent activation energy is $60.3 \mathrm{~kJ} / \mathrm{mol}$, which is lower than the intrinsic activation energy of $92.9 \mathrm{~kJ} / \mathrm{mol}$ due to the exothermic adsorption of reactants. The proposed rate equations are applicable to liquid phase HDO of fatty acids, and not limited to palmitic acid.

The kinetic model we present in this work can be used for the preliminary sizing of the reactor and the techno-economic analysis (TEA) of this hydrotreating process. The challenges that need to be overcome to obtain meaningful kinetic data have been identified. Finally, a systematic procedure for kinetic study has been developed, which when adopted, will minimize the number of kinetic study experiments that need to be performed Therefore, we consider our work to be an important asset to this green diesel production process. 


\section{Acknowledgements}

The financial support by the DOE-Bioenergy Technologies Office through grant DE-EE0006063 is gratefully acknowledged. Special thanks to Dr. Suphan Kovenklioglu and Dr. Ronald S. Besser of Stevens Institute of Technology for their review and comments on this study. Special thanks to Dr. James Manganaro for his inspiring guidance, and the painstaking review of the experimental results as well as the manuscript. The authors, of course, bear the sole responsibility for any errors.

\section{References}

(1) U.S.E.I. Administration. https://www.eia.gov/forecasts/ieo/, Last accessed April 28, 2016.

(2) International Energy Agency. Key world energy statistics. International Energy Agency, 2014.

(3) Hall, D. (2007). By the Numbers: Greenhouse Gas Emissions and the Fossil-Fuel Supply Chain in the United States. Assessing US Climate Policy Options, 23-37.

(4) Melero, J. A., Iglesias, J., \& Garcia, A. (2012). Biomass as renewable feedstock in standard refinery units. Feasibility, opportunities and challenges. Energy \& Environmental Science, 5(6), 7393-7420.

(5) Zhou, L., \& Lawal, A. (2016). Hydrodeoxygenation of microalgae oil to green diesel over Pt, Rh and presulfided NiMo catalysts. Catalysis Science \& Technology (2016): $6,1442-1454$.

(6) Zhou, L., \& Lawal, A. (2014). Evaluation of Presulfided NiMo $/ \gamma-\mathrm{Al} 2 \mathrm{O} 3$ for Hydrodeoxygenation of Microalgae Oil To Produce Green Diesel. Energy \& Fuels, 29(1), 262-272.

(7) Peng, B., Yao, Y., Zhao, C., \& Lercher, J. A. (2012). Towards Quantitative Conversion of Microalgae Oil to Diesel - Range Alkanes with Bifunctional Catalysts. Angewandte Chemie, 124(9), 2114-2117.

(8) Kubička, D., \& Kaluža, L. (2010). Deoxygenation of vegetable oils over sulfided Ni, Mo and NiMo catalysts. Applied Catalysis A: General, 372(2), 199-208.

(9) Huber, George W., Paul O'Connor, and Avelino Corma. "Processing biomass in conventional oil refineries: production of high quality diesel by hydrotreating vegetable oils in heavy vacuum oil mixtures." Applied Catalysis A: General 329 (2007): 120-129.

(10) da Rocha Filho, G. N., Brodzki, D., \& Djéga-Mariadassou, G. (1993). Formation of alkanes, alkylcycloalkanes and alkylbenzenes during the catalytic hydrocracking of vegetable oils. Fuel, 72(4), 543-549.

(11) Şenol, O. İ., Viljava, T. R., \& Krause, A. O. I. (2005). Hydrodeoxygenation of methyl esters on sulphided NiMo/ $\gamma$-Al 2 O 3 and CoMo/ $\gamma$-Al 2 O 3 catalysts. Catalysis Today, 100(3), 331-335. 
(12) Zuo, H., Liu, Q., Wang, T., Ma, L., Zhang, Q., \& Zhang, Q. (2012). Hydrodeoxygenation of methyl palmitate over supported Ni catalysts for diesel-like fuel production. Energy \& Fuels, 26(6), 3747-3755.

(13) Boda, L., Onyestyák, G., Solt, H., Lónyi, F., Valyon, J., \& Thernesz, A. (2010). Catalytic hydroconversion of tricaprylin and caprylic acid as model reaction for biofuel production from triglycerides. Applied Catalysis A: General, 374(1), 158-169.

(14) Madsen, A. T., Christensen, C. H., Fehrmann, R., \& Riisager, A. (2011). Hydrodeoxygenation of waste fat for diesel production: Study on model feed with Pt/alumina catalyst. Fuel, 90(11), 3433-3438.

(15) Hollak, S. A., Bitter, J. H., van Haveren, J., de Jong, K. P., \& van Es, D. S. (2012). Selective deoxygenation of stearic acid via an anhydride pathway. RSC Advances, 2(25), 9387-9391.

(16) Snåre, M., Kubičková, I., Mäki-Arvela, P., Eränen, K., Wärnå, J., \& Murzin, D. Y. (2007). Production of diesel fuel from renewable feeds: kinetics of ethyl stearate decarboxylation. Chemical Engineering Journal, 134(1), 29-34.

(17) Kumar, P., Yenumala, S. R., Maity, S. K., \& Shee, D. (2014). Kinetics of hydrodeoxygenation of stearic acid using supported nickel catalysts: Effects of supports. Applied Catalysis A: General, 471, 28-38.

(18) Ayodele, O. B., Farouk, H. U., Mohammed, J., Uemura, Y., \& Daud, W. M. A. W. (2015). Hydrodeoxygenation of oleic acid into n-and iso-paraffin biofuel using zeolite supported fluoro-oxalate modified molybdenum catalyst: Kinetics study. Journal of the Taiwan Institute of Chemical Engineers, 50, 142-152.

(19) Tike, M. A., \& Mahajani, V. V. (2007). Kinetics of hydrogenation of palm stearin fatty acid over $\mathrm{Ru} / \mathrm{A} 12 \mathrm{O} 3$ catalyst in presence of small quantity of water. Indian journal of chemical technology, 14(1), 52-63.

(20) Grilc, M., B. Likozar, and J. Levec. "Hydrotreatment of solvolytically liquefied lignocellulosic biomass over $\mathrm{NiMo} / \mathrm{Al} \quad 2 \quad \mathrm{O} \quad 3$ catalyst: reaction mechanism, hydrodeoxygenation kinetics and mass transfer model based on FTIR." Biomass and Bioenergy 63 (2014): 300-312.

(21) Grilc, M., B. Likozar, and J. Levec. "Hydrodeoxygenation and hydrocracking of solvolysed lignocellulosic biomass by oxide, reduced and sulphide form of NiMo, Ni, Mo and Pd catalysts." Applied Catalysis B: Environmental 150 (2014): 275-287.

(22) Grilc, Miha, Blaž Likozar, and Janez Levec. "Simultaneous liquefaction and hydrodeoxygenation of lignocellulosic biomass over NiMo/Al2O3, Pd/A12O3, and zeolite Y catalysts in hydrogen donor solvents." ChemCatChem 8.1 (2016): 180-191.

(23) Tadepalli, S.; Halder, R.; Lawal, A. Catalytic hydrogenation of onitroanisole in a microreactor: Reactor performance and kinetic studies. Chem. Eng. Sci. 2007, 62 (10), 2663-2678.

(24) Tadepalli, Sunitha, and Adeniyi Lawal. "The catalytic hydrogenation of aromatic nitro ketone in a microreactor: Reactor performance and kinetic studies."International Journal of Chemical Reactor Engineering 6.1 (2008).

(25) Joshi, N.; Lawal, A. Hydrodeoxygenation of pyrolysis oil in a microreactor. Chem. Eng. Sci. 2012, 74, 1-8. 
(26) Joshi, N.; Lawal, A. Hydrodeoxygenation of 4-Propylguaiacol (2-Methoxy-4propylphenol) in a Microreactor: Performance and Kinetic Studies. Ind. Eng. Chem. Res. 2013, 52 (11), 4049-4058.

(27) Joshi, N.; Lawal, A. Hydrodeoxygenation of acetic acid in a microreactor. Chem. Eng. Sci. 2012, 84, 761-771.

(28) H.S. Fogler, Elements of Chemical Reaction Engineering, Prentice-Hall, Englewood Cliffs, NJ, 1992, Ch. 12.

(29) M.A. Matthews, J.B. Rodden, A. Akgerman, Journal of Chemical and Engineering Data 32 (1987) 319-322.

(30) Mears, D. E. (1971). Tests for transport limitations in experimental catalytic reactors. Industrial \& Engineering Chemistry Process Design and Development, 10(4), 541-547.

(31) Mears, D. E. (1971). Diagnostic criteria for heat transport limitations in fixed bed reactors. Journal of Catalysis, 20(2), 127-131.

(32) Ajmera, S. K., Delattre, C., Schmidt, M. A., \& Jensen, K. F. (2002). Microfabricated differential reactor for heterogeneous gas phase catalyst testing. Journal of Catalysis, 209(2), 401-412.

(33) Janda, V., Vasek, P., Bizova, J., \& Belohlav, Z. (2004). Kinetic models for volatile chlorinated hydrocarbons removal by zero-valent iron. Chemosphere, 54(7), 917-925.

(34) Cheng, C. K., Foo, S. Y., \& Adesina, A. A. (2010). Glycerol steam reforming over bimetallic $\mathrm{Co}^{-} \mathrm{Ni} / \mathrm{Al} 2 \mathrm{O} 3$. Industrial \& Engineering Chemistry Research, 49(21), 10804-10817.

(35) Santana, R. C., Jongpatiwut, S., Alvarez, W. E., \& Resasco, D. E. (2005). Gasphase kinetic studies of tetralin hydrogenation on PT/alumina. Industrial \& engineering chemistry research, 44(21), 7928-7934.

(36) Schmidt, A., \& Schomäcker, R. (2007). Kinetics of 1, 5-cyclooctadiene hydrogenation on $\mathrm{Pd} / \alpha$-al2o3. Industrial \& engineering chemistry research, 46(6), 1677-1681.

(37) Lestari, S., Mäki-Arvela, P., Simakova, I., Beltramini, J., Lu, G. M., \& Murzin, D. Y. (2009). Catalytic deoxygenation of stearic acid and palmitic acid in semibatch mode. Catalysis letters, 130(1-2), 48-51.

(38) Fu, J., Lu, X., \& Savage, P. E. (2011). Hydrothermal decarboxylation and hydrogenation of fatty acids over Pt/C. ChemSusChem, 4(4), 481-486.

(39) Simakova, I., Simakova, O., Mäki-Arvela, P., \& Murzin, D. Y. (2010). Decarboxylation of fatty acids over Pd supported on mesoporous carbon. Catalysis Today, 150(1), 28-31. 


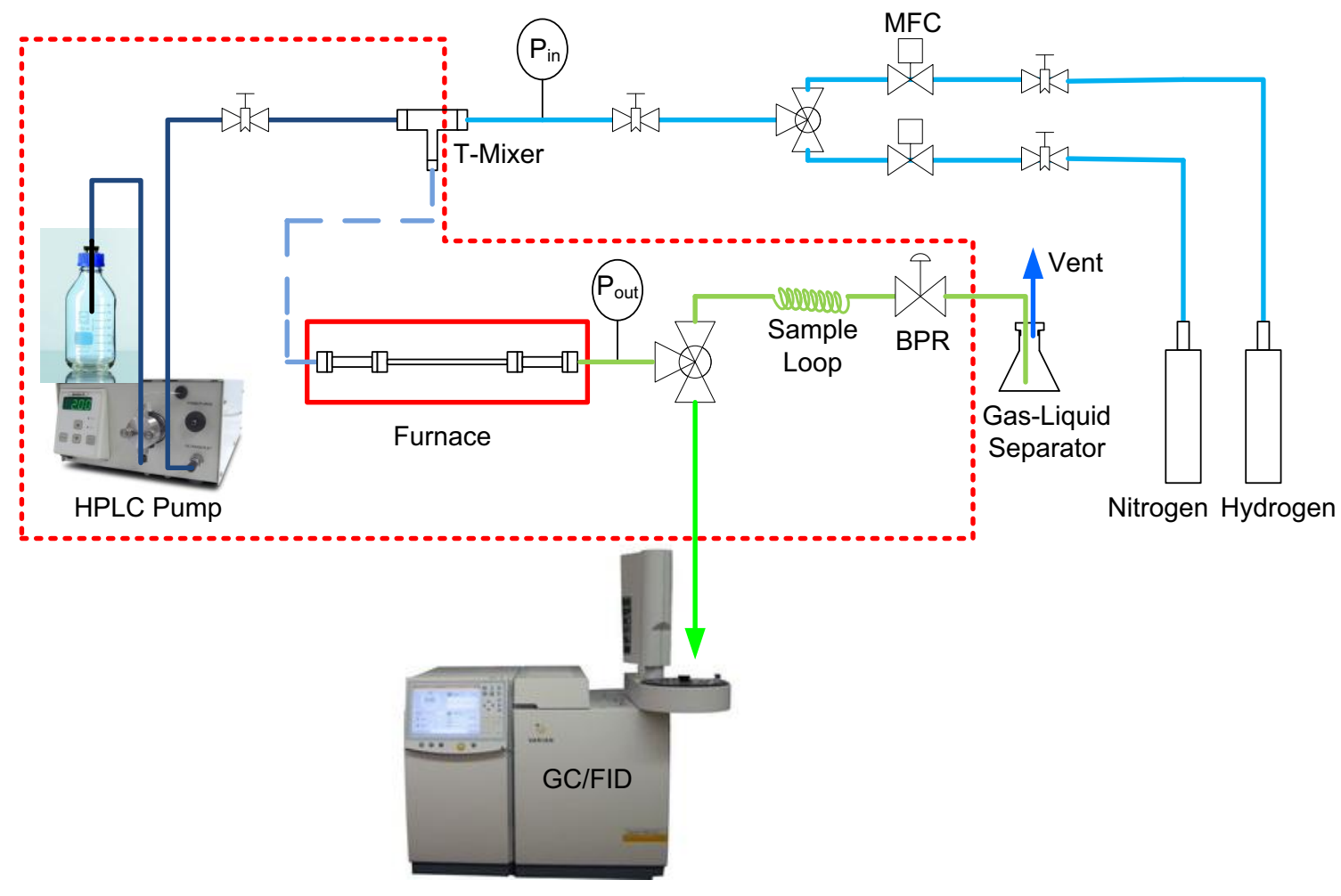

Figure 1. Schematic of Kinetic Study Setup 


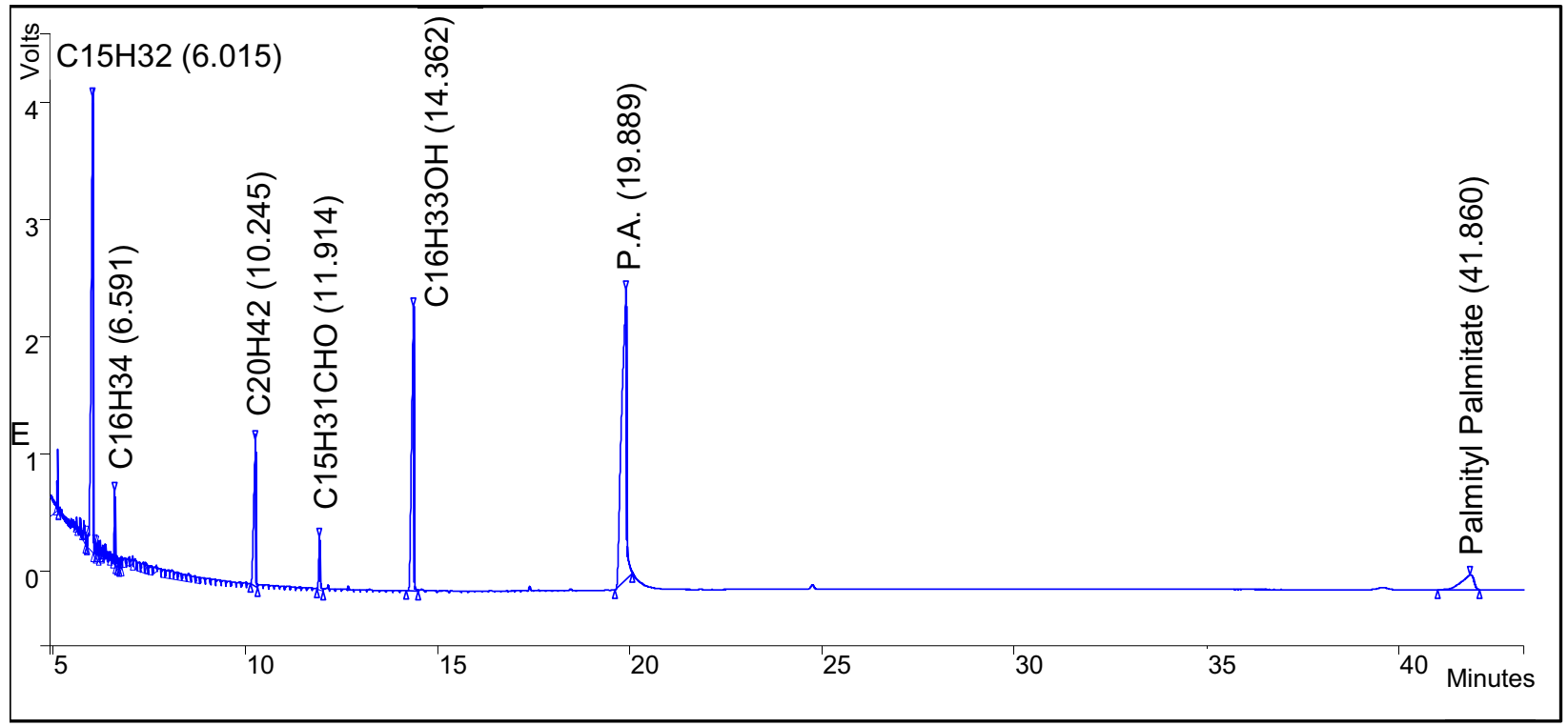

Figure 2. Chromatograms of preliminary experimental product $(29.4 \mathrm{mg}$ catalyst, $1.0 \mathrm{wt} \%$ P.A. in dodecane, $0.25 \mathrm{ml} / \mathrm{min}$, Temperature $=375^{\circ} \mathrm{C}$, Reaction pressure $=500 \mathrm{psig}, \mathrm{H}_{2}$ flow rate $=250$ $\mathrm{sccm}$ ) 


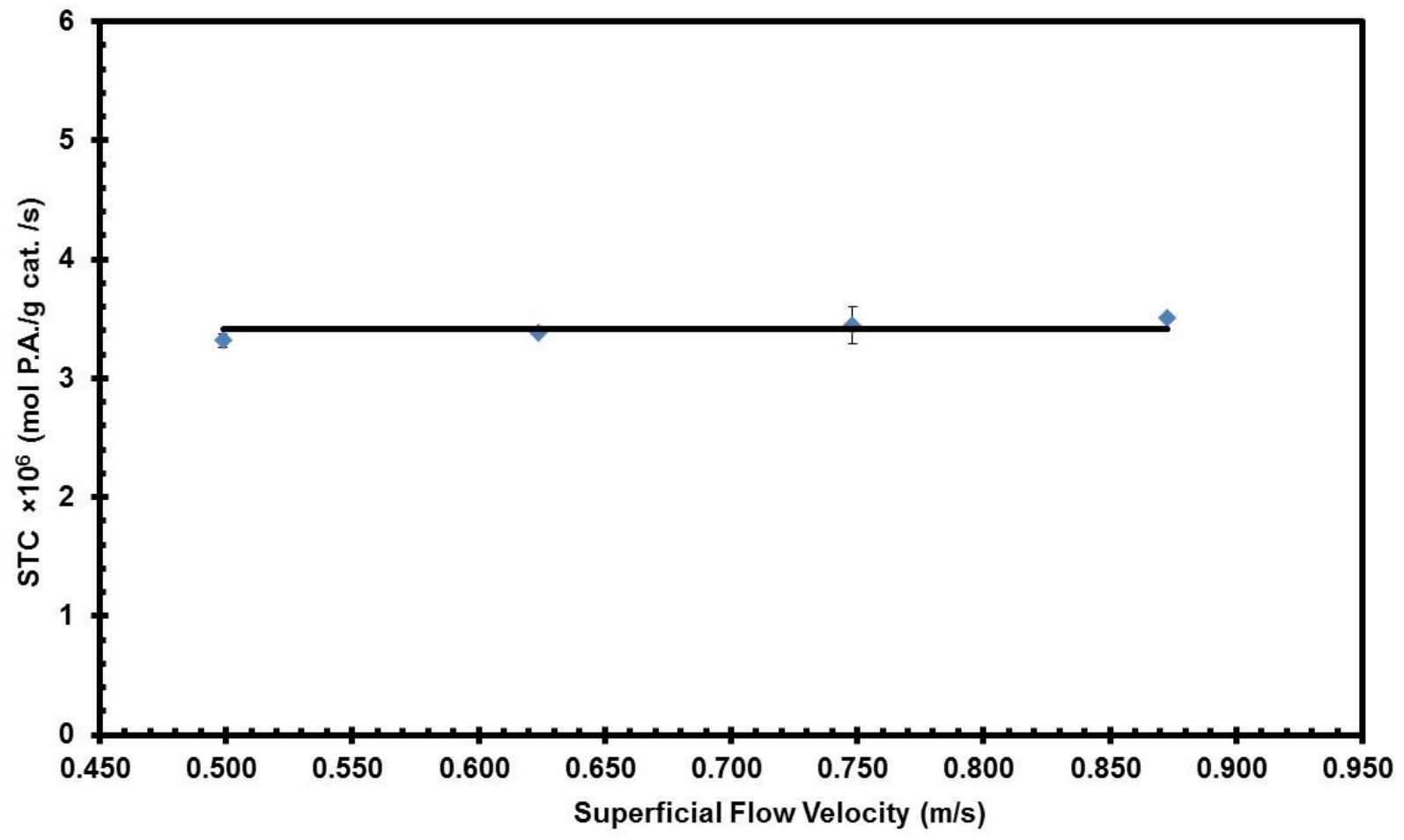

Figure 3. Effect of superficial flow velocity on space-time consumption of Palmitic acid. (1.0 wt \% P.A. in dodecane, Temperature $=360{ }^{\circ} \mathrm{C}, \mathrm{H}_{2}$ pressure $=500 \mathrm{psig}$, Residence time $=0.06 \mathrm{~s}, \mathrm{H}_{2} /$ Liquid feed $=1000 \mathrm{SmL} / \mathrm{mL}$ ). 

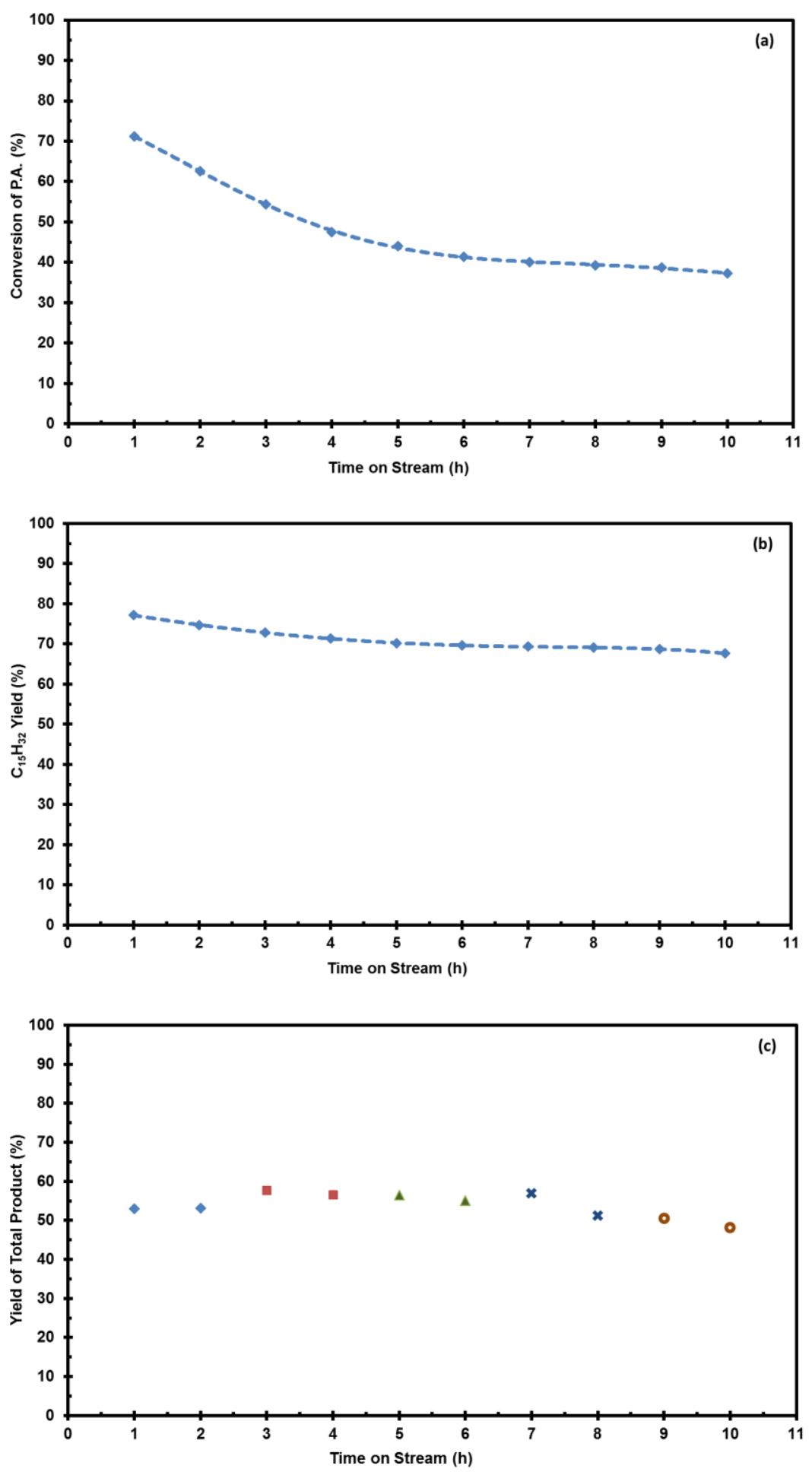

Figure 4. Stability of catalyst activity and selectivity (14.2 mg catalyst, $1.0 \mathrm{wt} \%$ P.A. in dodecane, Temperature $=350^{\circ} \mathrm{C}$, Reaction pressure $=500 \mathrm{psig}$, (a) \& (b) $0.2 \mathrm{ml} / \mathrm{min}, \mathrm{H}_{2}$ flow rate $=200 \mathrm{sccm}$, (c) $0.15 \mathrm{ml} / \mathrm{min}, \mathrm{H}_{2}$ flow rate $=150 \mathrm{sccm}$, on-stream regeneration every 2 hours). 

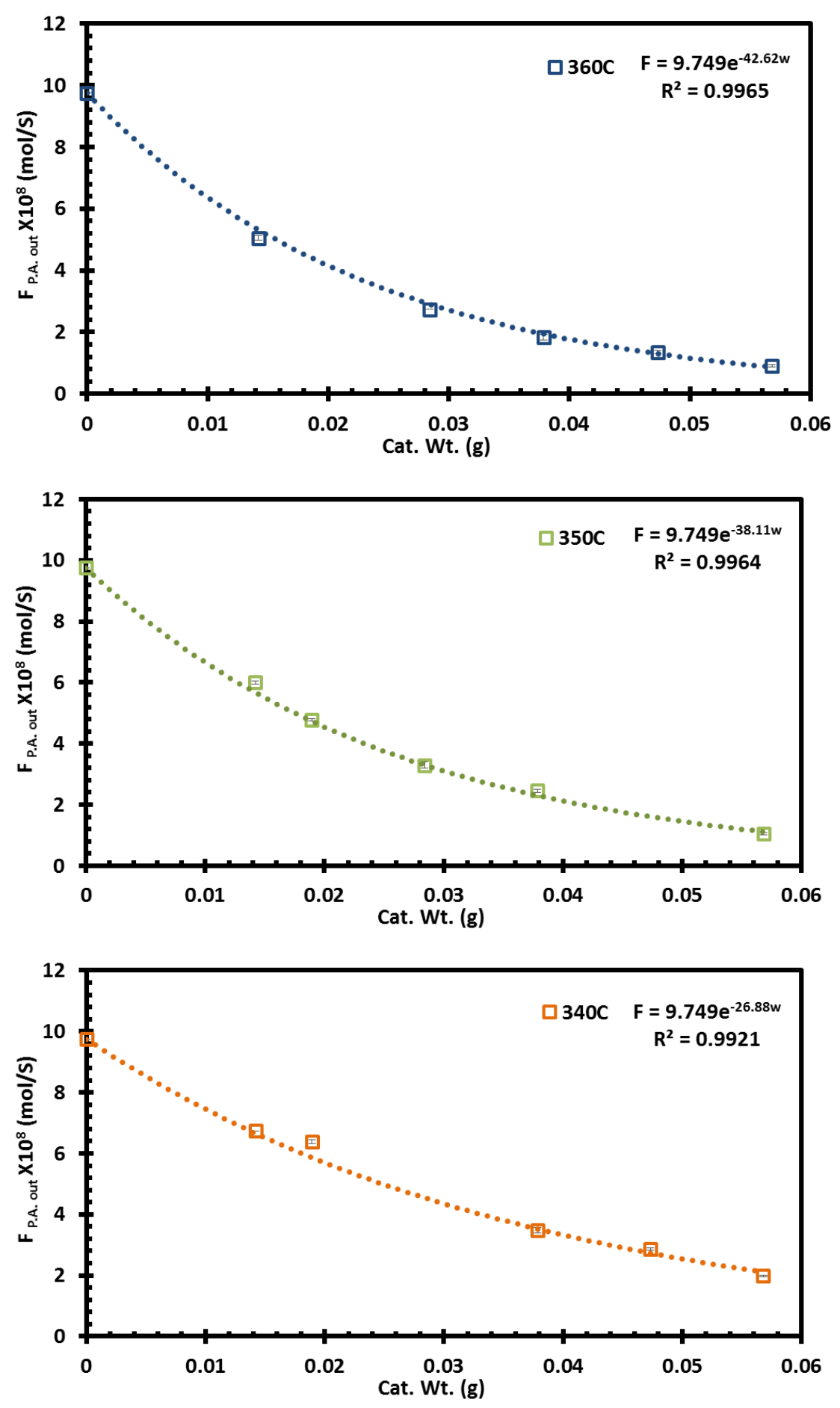

Figure 5. Dependence of Palmitic acid molar flow rate at exit on catalyst load at different reaction temperature $\left(1.0 \mathrm{wt} \%\right.$ P.A. in dodecane, $0.2 \mathrm{ml} / \mathrm{min}, \mathrm{H}_{2}$ pressure $=500$ psig, $\mathrm{H}_{2}$ flow rate $=200 \mathrm{sccm}$ ). 

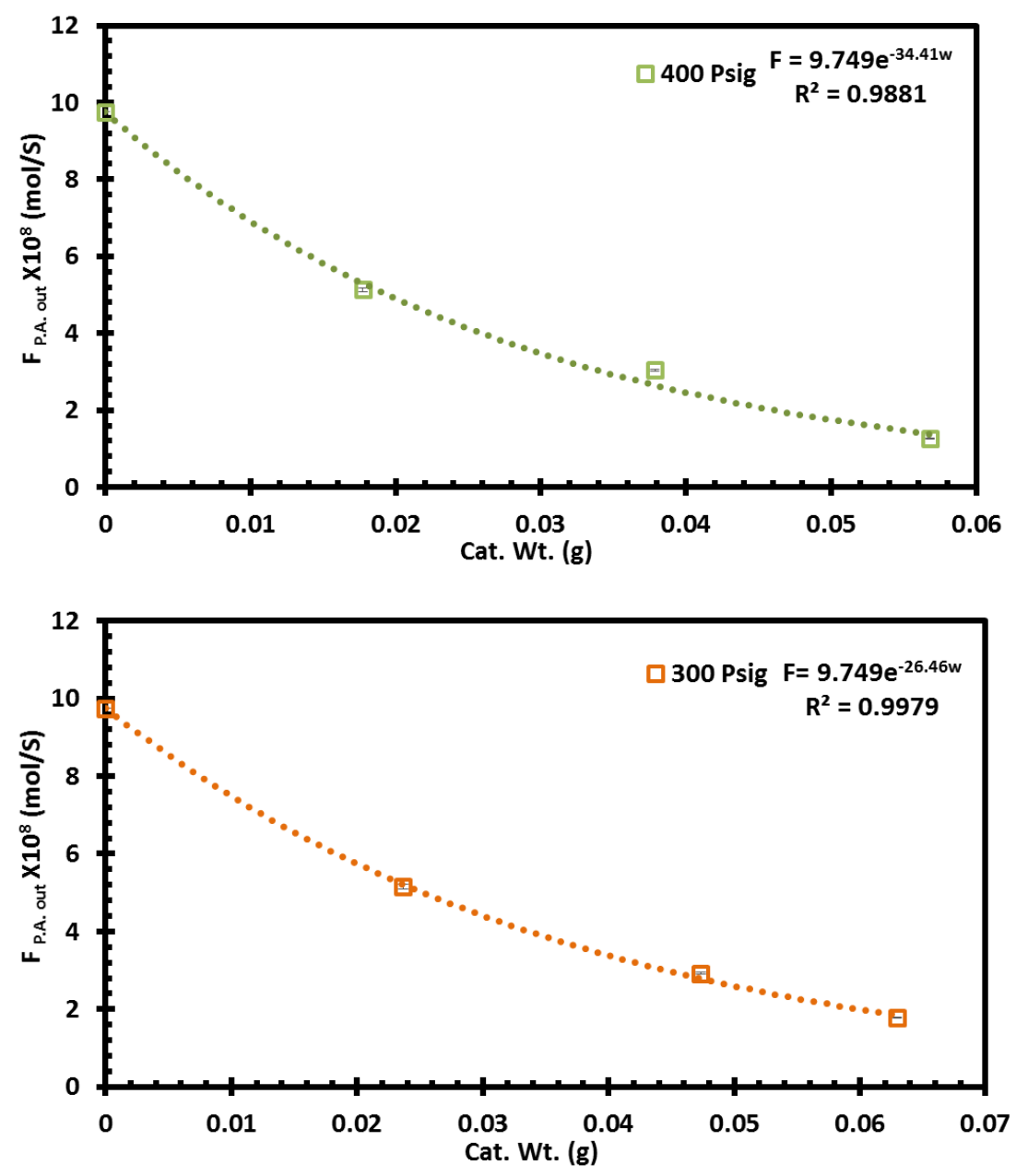

Figure 6. Dependence of Palmitic acid molar flow rate at exit on catalyst load at different reaction Pressure $\left(1.0 \mathrm{wt} \%\right.$ P.A. in dodecane, $0.2 \mathrm{ml} / \mathrm{min}$, Reaction Temperature $=360^{\circ} \mathrm{C}$, $\mathrm{H}_{2}$ flow rate $\left.=200 \mathrm{sccm}\right)$. 
Table 1 Estimation of kinetic parameters from different kinetic models at $350^{\circ} \mathrm{C}$.

\begin{tabular}{|c|c|c|c|c|}
\hline \multirow[t]{2}{*}{ Model } & \multirow[t]{2}{*}{ Expression } & \multirow[t]{2}{*}{ Parameters } & \multicolumn{2}{|c|}{ Model Discrimination } \\
\hline & & & $\begin{array}{l}95 \% \\
\text { Confidence }\end{array}$ & \\
\hline \multirow[t]{3}{*}{ Power Law } & $r_{P . A .}=-k_{r x n} C_{P . A .}^{\alpha} P_{H_{2}}^{\beta}$ & $\mathrm{k}_{\mathrm{rxn}}=3.94 \mathrm{e}-11 \mathrm{~m}^{3} \mathrm{~s}^{-1} \mathrm{~g}^{-1} \mathrm{kPa}^{-0.99}$ & $1.12 \mathrm{e}-12$ & 0.998 \\
\hline & & $\alpha=1.02$ & $1.18 \mathrm{e}-2$ & \\
\hline & & $\beta=0.990$ & $4.49 \mathrm{e}-3$ & \\
\hline \multirow[t]{4}{*}{ Eley-Rideal } & $r_{-}=-k_{r x n} C_{P . A .} P_{H_{2}}$ & $\mathrm{k}_{\mathrm{rxn}}=3.68 \mathrm{e}-11 \mathrm{~m}^{3} \mathrm{~s}^{-1} \mathrm{~g}^{-1} \mathrm{kPa}^{-1}$ & $2.28 \mathrm{e}-15$ & 0.999 \\
\hline & $r_{P . A .}=-\overline{1+K_{H_{2}} P_{H_{2}}}$ & $\mathrm{~K}_{\mathrm{H} 2}=3.70 \mathrm{e}-6 \mathrm{kPa}^{-1}$ & $2.17 \mathrm{e}-8$ & \\
\hline & $k_{r x n} C_{P . A .}\left(P_{H_{2}}\right)^{0.5}$ & $\mathrm{k}_{\mathrm{rxn}}=1.51 \mathrm{e}-9 \mathrm{~m}^{3} \mathrm{~s}^{-1} \mathrm{~g}^{-1} \mathrm{kPa}^{-0.5}$ & $1.06 \mathrm{e}-10$ & 0.955 \\
\hline & $r_{P . A .}=-\overline{1+\left(K_{H_{2}} P_{H_{2}}\right)^{0.5}}$ & $\mathrm{~K}_{\mathrm{H} 2}=1.12 \mathrm{e}-33 \mathrm{kPa}^{-1}$ & $3.01 \mathrm{e}-18$ & \\
\hline \multirow{15}{*}{$\begin{array}{l}\text { Langmuir- } \\
\text { Hinshelwood }\end{array}$} & $r_{D}=-\frac{k_{r x n} K_{P . A .} C_{P . A .} K_{H_{2}} P_{H_{2}}}{2}$ & $\mathrm{k}_{\mathrm{rxn}}=2.15 \mathrm{~mol} \mathrm{~s}^{-1} \mathrm{~g}^{-1}$ & $1.21 \mathrm{e}-3$ & 0.999 \\
\hline & $r_{P . A .}=-\overline{\left(1+K_{P . A .} C_{P . A .}\right)\left(1+K_{H_{2}} P_{H_{2}}\right)}$ & $\mathrm{K}_{\mathrm{P} . \mathrm{A} .}=4.60 \mathrm{e}-6 \mathrm{~m}^{3} \mathrm{~mol}^{-1}$ & $2.60 \mathrm{e}-9$ & \\
\hline & $\begin{array}{l}\text { - Non-dissociative adsorption of } \mathrm{H}_{2} \\
\text { - Non-dissociative adsorption of P.A. }\end{array}$ & $\mathrm{K}_{\mathrm{H} 2}=3.72 \mathrm{e}-6 \mathrm{kPa}^{-1}$ & $2.12 \mathrm{e}-9$ & \\
\hline & $r_{P A}=-\frac{k_{r x n} C_{P . A .} P_{H_{2}}}{2}$ & $\mathrm{k}_{\mathrm{rxn}}=3.72 \mathrm{e}-11 \mathrm{~m}^{3} \mathrm{~s}^{-1} \mathrm{~g}^{-1} \mathrm{kPa}^{-1}$ & $4.27 \mathrm{e}-15$ & 0.999 \\
\hline & $r_{P . A .}=-\overline{\left(1+K_{P . A .} C_{P . A .}\right)\left(1+\left(K_{H_{2}} P_{H_{2}}\right)^{0.5}\right)^{2}}$ & $\mathrm{~K}_{\mathrm{P} . \mathrm{A} .}=1.06 \mathrm{e}-6 \mathrm{~m}^{3} \mathrm{~mol}^{-1}$ & $1.74 \mathrm{e}-6$ & \\
\hline & - Dual site adsorption & $\mathrm{K}_{\mathrm{H} 2}=3.77 \mathrm{e}-8 \mathrm{kPa}^{-1}$ & $3.90 \mathrm{e}-10$ & \\
\hline & $\begin{array}{l}\text { - } \quad \text { Dissociative adsorption of } \mathrm{H}_{2} \\
\text { - Non-dissociative adsorption of P.A. }\end{array}$ & & & \\
\hline & $r_{P . A .}=-\frac{k_{r x n} C_{P . A .} P_{H_{2}}}{\left(1+K_{D} C_{D .1}+K_{H} P_{H}\right)^{2}}$ & $\mathrm{k}_{\mathrm{rxn}}=3.68 \mathrm{e}-11 \mathrm{~m}^{3} \mathrm{~s}^{-1} \mathrm{~g}^{-1} \mathrm{kPa}^{-1}$ & $2.86 \mathrm{e}-15$ & 0.999 \\
\hline & - Single site adsorntion & $\mathrm{K}_{\mathrm{P} . \mathrm{A} .}=9.90 \mathrm{e}-7 \mathrm{~m}^{3} \mathrm{~mol}^{-1}$ & $9.15 \mathrm{e}-7$ & \\
\hline & - Non-dissociative adsorption of $\mathrm{H}_{2}$ & $\mathrm{~K}_{\mathrm{H} 2}=1.84 \mathrm{e}-6 \mathrm{kPa}^{-1}$ & $1.09 \mathrm{e}-8$ & \\
\hline & $\begin{array}{l}\text { - Non-dissociative adsorption of P.A. } \\
k_{r \times n} C_{P . A .}\left(P_{H_{2}}\right)^{0.5}\end{array}$ & & & \\
\hline & $r_{P . A .}=-\overline{\left(1+K_{P A} C_{P_{A}}+\left(K_{H_{0}} P_{H_{0}}\right)^{0.5}\right)^{2}}$ & $\mathrm{k}_{\mathrm{rxn}}=1.98 \mathrm{e}-9 \mathrm{~m}^{3} \mathrm{~s}^{-1} \mathrm{~g}^{-1} \mathrm{kPa}^{-0.5}$ & $1.56 \mathrm{e}-10$ & 0.963 \\
\hline & 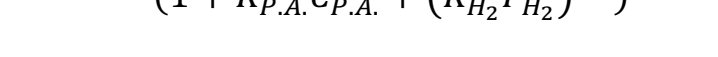 & $\mathrm{K}_{\text {P.A. }}=9.50 \mathrm{e}-4 \mathrm{~m}^{3} \mathrm{~mol}^{-1}$ & $5.90 \mathrm{e}-4$ & \\
\hline & - $\quad$ Single site adsorption & $\mathrm{K}_{\mathrm{H} 2}=0 \mathrm{kPa}^{-1}$ & $8.54 \mathrm{e}-8$ & \\
\hline & $\begin{array}{l}\text { - } \\
\text { - } \quad \text { Nissociative adsorption of } \mathrm{H}_{2} \\
\text { dissociative adsorption of P.A. }\end{array}$ & & & \\
\hline
\end{tabular}


Table 2 Summary of kinetic constants for different kinetic models.

Model Expression Parameters

\begin{tabular}{|c|c|c|}
\hline Power Law & $\begin{aligned} r_{P . A .} & =-k_{r x n} C_{P . A . A}^{\alpha} P_{H_{2}}^{\beta} \\
k_{r x n} & =A e^{-\frac{E_{a}}{R T}}\end{aligned}$ & $\begin{array}{l}\mathrm{A}=4.31 \mathrm{e}-6 \mathrm{~m}^{3} \mathrm{~s}^{-1} \mathrm{~g}^{-1} \mathrm{kPa}^{-0.99} \\
\mathrm{Ea}=60.3 \mathrm{~kJ} / \mathrm{mol} \\
\alpha=1.02 \\
\beta=0.990\end{array}$ \\
\hline Eley-Rideal & $\begin{aligned} r_{P . A .} & =-\frac{k_{r x n} C_{P . A .} P_{H_{2}}}{1+K_{H_{2}} P_{H_{2}}} \\
k_{r x n} & =A e^{-\frac{E_{a}}{R T}} \\
K_{H_{2}} & =B e^{-\frac{\Delta H_{H_{2}}}{R T}}\end{aligned}$ & $\begin{array}{l}\mathrm{A}=3.99 \mathrm{e}-6 \mathrm{~m}^{3} \mathrm{~s}^{-1} \mathrm{~g}^{-1} \mathrm{kPa}^{-1} \\
\mathrm{Ea}=60.3 \mathrm{~kJ} / \mathrm{mol} \\
\mathrm{B}=2.00 \mathrm{e}-6 \mathrm{kPa}^{-1} \\
\Delta \mathrm{H}_{\mathrm{H} 2}=-3.18 \mathrm{~kJ} / \mathrm{mol}\end{array}$ \\
\hline $\begin{array}{l}\text { Langmuir- } \\
\text { Hinshelwood }\end{array}$ & $\begin{aligned} r_{P . A .} & =-\frac{k_{r x n} K_{P . A .} C_{P . A} K_{H_{2}} P_{H_{2}}}{\left(1+K_{P . A .} C_{P . A .}\right)\left(1+K_{H_{2}} P_{H_{2}}\right)} \\
k_{r x n} & =A e^{-\frac{E_{a}}{R T}} \\
K_{H_{2}} & =B e^{-\frac{\Delta H_{H_{2}}}{R T}} \\
K_{P . A .} & =C e^{-\frac{\Delta H_{P . A .}}{R T}}\end{aligned}$ & $\begin{array}{l}\mathrm{A}=1.27 \mathrm{e}+8 \mathrm{~mol} \mathrm{~s}^{-1} \mathrm{~g}^{-1} \\
\mathrm{Ea}=92.9 \mathrm{~kJ} / \mathrm{mol}^{-1} \\
\mathrm{~B}=1.31 \mathrm{e}-6 \mathrm{kPa}^{-1} \\
\Delta \mathrm{H}_{\mathrm{H} 2}=-5.42 \mathrm{~kJ} / \mathrm{mol} \\
\mathrm{C}=2.38 \mathrm{e}-8 \mathrm{~mol} \mathrm{~m} \\
\Delta \mathrm{H}_{\text {P.A. }}=-27.3 \mathrm{~kJ} / \mathrm{mol}\end{array}$ \\
\hline
\end{tabular}

